\title{
KECEMASAN MAHASISWA DI PULAU JAWA PADA MASA PANDEMI COVID-19
}

\author{
Puji Laksmini, Nissa Noor Annashr, Taufiq Firdaus A.Atmadja \\ Universitas Siliwangi \\ pujilaksmini@gmail.com
}

\begin{abstract}
Abstrak
Pulau Jawa memiliki jumlah kasus COVID-19 tertinggi diantara pulau-pulau lainnya di Indonesia. Proporsi kasus tertinggi berdasarkan provinsi yakni DKI Jakarta $(24,4 \%)$, jawa barat (16,9\%), Jawa Tengah $(11,00 \%)$, Jawa Timur $(8,8 \%)$, sedangkan untuk Banten (2,8\%). Pandemi COVID-19 ini merubah seluruh aspek kehidupan manusia di seluruh dunia, tidak hanya secara material namun juga non material. Banyaknya informasi yang menjelaskan bahwa COVID-19 menyebabkan kematian membuat individu merasa cemas yang berlebih. Penelitian ini menggunakan desain kuantitatif analitik melalui pendekatan cross sectional. Populasinya adalah mahasiswa yang tinggal di Pulau Jawa, dan sampel yang digunakan sejumlah 2014 mahasiswa dan diambil secara purposive sampling. Hasil penelitian ini adalah sebagian besar responden mahasiswa mengalami kecemasan tinggi yakni sebesar 52,9\%. Variabel yang berhubungan dengan tingkat kecemasan adalah jenis kelamin dan jurusan kuliah (nilai $\mathrm{p}<0,05$ ), sedangkan variabel yang tidak berhubungan adalah status ekonomi dan kelompok usia. Kondisi pandemi yang masih berlangsung dan tidak dapat diprediksi kapan berakhirnya ini memerlukan peran serta dari berbagai pihak untuk mengurangi kecemasan yang terjadi di masyarakat khususnya di kalangan mahasiswa.
\end{abstract}

Kata Kunci: Kecemasan ; COVID-19 ; Mahasiswa ; Jawa

\section{Pendahuluan}

Berawal dari akhir tahun 2019 hingga sekarang, dunia masih berjuang melawan pandemi COVID-19. WHO mencatat per tanggal 6 Mei 2021, jumlah kasus terkonfirmasi positif COVID-19 di seluruh dunia sebanyak 154.815.600 dengan jumlah kematian sebesar 3.236.104. Kawasan Asia Tenggara memiliki jumlah kasus : 24.269.809 (WHO, 2021). Sedangkan kondisi di Indonesia sendiri saat ini (per tanggal 6 
JURNAL ILMU KESEHATAN BHAKTI HUSADA:

HEALTH SCIENCES JOURNAL, VOL. 12 No. 01, JUNI 2021

DOI: $10.34305 /$ jikbh.v12i1.274
Ciptaan disebarluaskan di bawah

Lisensi Creative Commons Atribusi-

NonKomersial-BerbagiSerupa 4.0 Internasional.

tekanan darah, dan lain sebagainya Okazaki dalam (Fitria \& Ifdil, 2020). Hasil penelitian oleh (Natalya, 2020) kurang lebih 70\% responden dari berbagai usia mengalami kecemasan yakni kecemasan ringan, sedang, berat, dan sangat berat. Begitu juga penelitian yang dilakukan oleh (Guslinda et al., 2020) menyatakan bahwa sebanyak $80 \%$ lansia dari total 110 responden mengeluh cemas terkait dampak pandemi COVID19. Kecemasan ini menurunkan imunitas fisik dan memperburuk kondisi lansia.

seluruh aspek kehidupan manusia di seluruh dunia, tidak hanya secara material namun juga non material. Aspek kesehatan, sosial, ekonomi, agama, dan aspek lainnya terdampak akibat pandemi ini. Salah satu akibat yang menonjol dari hal ini adalah aspek kejiwaan dari masyarakat dari seluruh lapisan usia yang ada. Banyaknya informasi yang menjelaskan bahwa COVID-19 menyebabkan kematian membuat individu merasa cemas yang berlebih (Zulva, 2020). Menurut American Psychological Association (APA), kecemasan merupakan keadaan emosi yang muncul saat individu sedang stress, dan ditandai oleh perasaan tegang, pikiran yang membuat individu merasa khawatir dan disertai respon fisik (jantung berdetak kencang, naiknya
Mokrue dalam (Walean et al., 2021) menyatakan bahwa Anxiety and Depression of America menjelaskan bahwa perguruan tinggi adalah waktu yang menyenangkan. Namun masa perkuliahan memiliki banyak tantangan dan seringkali mengakibatkan stres bagi banyak orang. Hal ini karena banyak orang perlu melakukan penyesuaian dengan adanya masa transisi dari kehidupan sekolah biasa ke kehidupan perkuliahan. Survei yang dilakukan oleh American College Health Association, menemukan bahwa $25.9 \%$ dan $31.9 \%$ mahasiswa dilaporkan mengalami kecemasan dan stres. Penelitian kepada mahasiswa oleh (Vahedian-Azimi A et al., 2020) menghasilkan bahwa level kecemasan lebih tinggi pada pria 
dibandingkan wanita, dan mahasiswa dengan IPK rendah lebih rentan mengalami cemas daripada mahasiswa yang memiliki IPK tinggi selama masa pandemi ini. Penelitian oleh (Febriyanti \& Mellu, 2020) menyatakan bahwa sebanyak 43,3\% mahasiswa di Kota Kupang mengalami kecemasan ringan, dan $56,7 \%$ mengalami kecemasan sedang akibat pandemi COVID-19. Penelitian ini akan mengungkap tentang kondisi kecemasan yang dialami oleh mahasiswa di Pulau Jawa pada masa pandemi COVID-19.

\section{Metode}

Penelitian menggunakan desain kuantitatif analitik melalui pendekatan cross sectional. Populasinya adalah mahasiswa yang tinggal di Pulau Jawa, dan sampel yang digunakan sejumlah 2014 mahasiswa serta teknik pengambilan sampel dilakukan secara purposive sampling. Instrumen yang digunakan dalam penelitian ini adalah kuesioner tentang kecemasan pada mahasiswa yang telah dilakukan uji validitas dan reliabilitas dan telah dilakukan uji persetujuan etik. Kuesioner disebarkan kepada responden melalui aplikasi google form. Analisa statistik yang digunakan dalam penelitian ini adalah statistik deskriptif univariat dan bivariat menggunakan uji hi Square.

Hasil

Hasil penelitian ini penulis tunjukkan melalui tabel di bawah ini :

Tabel 1. Distribusi Responden Menurut Tingkat Kecemasan

\begin{tabular}{lcc}
\hline \multicolumn{1}{c}{$\begin{array}{c}\text { Tingkat } \\
\text { Kecemasan }\end{array}$} & Jumlah & Persentase \\
\hline Kecemasan rendah & 948 & 47,1 \\
Kecemasan tinggi & 1066 & 52,9 \\
\hline Total & $\mathbf{2 0 1 4}$ & $\mathbf{1 0 0}$ \\
\hline
\end{tabular}

Berdasarkan tabel 1, terlihat bahwa sebagian besar responden mahasiswa mengalami kecemasan tinggi yakni sebesar 52,9\%.

Tabel 2. Distribusi Responden Menurut Usia, Jenis Kelamin, 


\section{Status Ekonomi, dan Jurusan}

\begin{tabular}{|c|c|c|c|c|c|c|}
\hline \multirow[t]{3}{*}{ Variabel Independen } & \multicolumn{4}{|c|}{ Tingkat Kecemasan } & \multirow[t]{3}{*}{ p-Value } & \multirow[t]{3}{*}{ Nilai OR } \\
\hline & \multicolumn{2}{|c|}{$\begin{array}{c}\text { Kecemasan } \\
\text { Rendah }\end{array}$} & \multicolumn{2}{|c|}{$\begin{array}{c}\text { Kecemasan } \\
\text { Tinggi } \\
\end{array}$} & & \\
\hline & $\mathbf{N}$ & $\%$ & $\mathbf{N}$ & $\%$ & & \\
\hline $\begin{array}{r}\text { Usia } \\
-\quad \delta 18 \text { tahun } \\
-\quad>18 \text { tahun }\end{array}$ & $\begin{array}{c}340 \\
2305\end{array}$ & $\begin{array}{l}43,6 \\
44,8\end{array}$ & $\begin{array}{c}440 \\
2839\end{array}$ & $\begin{array}{l}56,4 \\
55,2\end{array}$ & 0,549 & 0,9 \\
\hline $\begin{array}{cc}\text { Jenis Kelamin } \\
-\quad \text { Laki-laki } \\
-\quad \text { Wanita }\end{array}$ & $\begin{array}{l}235 \\
713\end{array}$ & $\begin{array}{l}58,3 \\
44,3\end{array}$ & $\begin{array}{l}168 \\
898\end{array}$ & $\begin{array}{l}41,7 \\
55,7\end{array}$ & $0,0001 *$ & 1,8 \\
\hline $\begin{array}{cc}\text { Status Ekonomi } \\
\text { - } & \text { Tidak mampu } \\
- & \text { Menengah } \\
\text { - } & \text { Mampu }\end{array}$ & $\begin{array}{c}61 \\
660 \\
227\end{array}$ & $\begin{array}{l}49,2 \\
46,4 \\
48,4\end{array}$ & $\begin{array}{c}63 \\
761 \\
242\end{array}$ & $\begin{array}{l}50,8 \\
53,6 \\
51,6\end{array}$ & 0,677 & $\begin{array}{l}0,9 \\
1,1\end{array}$ \\
\hline \begin{aligned} \multicolumn{2}{l}{ Jurusan } \\
$-\quad$ Kesehatan \\
$-\quad$ Non Kesehatan \end{aligned} & $\begin{array}{l}319 \\
629\end{array}$ & $\begin{array}{l}42,1 \\
50,0\end{array}$ & $\begin{array}{l}438 \\
628\end{array}$ & $\begin{array}{l}57,9 \\
50,0\end{array}$ & 0,001* & 0,7 \\
\hline
\end{tabular}

Catatan : * menunjukkan adanya hubungan yang signifikan

\section{Pembahasan}

Hasil penelitian menunjukkan bahwa sebagian besar responden yang berpartisipasi mengalami kecemasan tinggi. Hasil ini sejalan dengan penelitian (C. Wang \& Zhao, 2020) yang menyatakan bahwa rata-rata skor kecemasan mahasiswa di China lebih tinggi secara signifikan daripada skor kecemasan yang normal. Begitu pula penelitian oleh (Vahedian-Azimi A et al., 2020) yang menghasilkan bahwa $97,3 \%$ dari 886 responden di Iran mengalami kecemasan berat. Kondisi yang mirip adalah penelitian dari (Biber

et al., 2020) yang melibatkan 1.640 mahasiswa di Perancis dimana sebanyak 49.0\% partisipan diklasifikasikan mengalami kecemasan ringan, 24,97\% kecemasan sedang, dan 25,89\% mengalami kecemasan berat. Wabah epidemi yang luas akan memberikan dampak negatif kepada individu dan masyarakat luas. Penelitian yang melibatkan 600 responden untuk mengetahui status psikologi selama pandemi COVID-19 menunjukkan bahwa rata-rata skor Self Rating Anxiety Scale (SAS) lebih tinggi daripada normal (Y. Wang et al., 2021). Beberapa faktor dapat menyebabkan kecemasan pada masa pandemi COVID-19. Menurut (Aulia, 2018) kecemasan dapat 
JURNAL ILMU KESEHATAN BHAKTI HUSADA:

HEALTH SCIENCES JOURNAL, VOL. 12 No. 01, JUNI 2021

DOI: $10.34305 /$ jikbh.v12i1.274
Ciptaan disebarluaskan di bawah

Lisensi Creative Commons Atribusi-

NonKomersial-BerbagiSerupa 4.0 Internasional.

kecemasan lebih banyak dialami oleh wanita dibandingkan laki-laki. Begitu pula penelitian dari (Y. Wang et al., 2021) yang menghasilkan bahwa kejadian kecemasan pada wanita 3,01 kali lebih besar daripada laki-laki.

Hasil penelitian ini juga menunjukkan bahwa variabel jurusan menghasilkan nilai $\mathrm{OR}=0,7$ yang artinya mahasiswa yang mengambil kuliah jurusan bidang kesehatan cenderung untuk mengalami kecemasan tinggi 1,4 kali lebih besar daripada mahasiswa di bidang non kesehatan. Penelitian oleh (Sari, 2020) yang melibatkan 70 mahasiswa keperawatan mengatakan bahwa stressor yang paling menyebabkan stress pada mereka adalah kesulitan memahami materi secara daring dan kekhawatiran tertular COVID-19. Kecemasan tinggi mahasiswa bidang kesehatan dimungkinkan terjadi karena mahasiswa kesehatan lebih memahami tentang patofisiologi penyakit COVID-19, bahaya yang dapat ditimbulkan, serta masih adanya sebagian masyarakat yang tidak percaya dengan penyakit ini sehingga mengabaikan protokol kesehatan yang telah dianjurkan. Hal tersebut mengakibatkan mahasiswa di systematic review dari (Walean et al., 2021) yang menyatakan bahwa 
Ciptaan disebarluaskan di bawah

Lisensi Creative Commons Atribusi- bidang kesehatan lebih aware dan takut/cemas tertular oleh penyakit ini.

Sebaliknya untuk variabel status ekonomi tidak memiliki hubungan yang signifikan dengan tingkat kecemasan pada mahasiswa dengan nilai $\mathrm{p}=0,677$. Hasil ini tidak sesuai dengan penelitian (Cao, Wenjun et al., 2020) mengatakan bahwa pengaruh keadaan finansial memiliki hubungan dengan munculnya kecemasan (nilai $\mathrm{p}<0,001$ ).

Hasil analisis variabel kelompok usia tidak memiliki hubungan yang signifikan dengan tingkat kecemasan pada mahasiswa. Hasil ini berbeda

\section{Kesimpulan}

Hasil penelitian menunjukkan bahwa sebagian besar (52,9\%) responden yang berpartisipasi mengalami kecemasan tinggi. Variabel yang berhubungan secara signifikan dengan tingkat kecemasan adalah jenis kelamin dan jurusan kuliah (nilai $\mathrm{p}<$ 0,05), sedangkan variabel yang tidak berhubungan dengan tingkat kecemasan adalah status ekonomi dan kelompok usia. dengan hasil penelitian oleh (Husky et al., 2020) yang menyatakan bahwa usia memiliki hubungan yang signifikan dengan kecemasan (nilai $\mathrm{p}<0,001$ ). Hal ini bisa saja terjadi karena perbedaan usia yang tidak terlalu jauh di antara mahasiswa yakni sekitar 18 -24 tahun atau bisa dikatakan remaja tingkat akhir dan dewasa awal, dimana usia tersebut memiliki karakteristik yang sama yakni kesiapan mental dan jiwa belum matang serta kurangnya pengalaman dalam manajemen kecemasannya (Febriyanti \& Mellu, 2020)

Kondisi pandemi yang masih berlangsung dan tidak dapat diprediksi kapan berakhirnya ini memerlukan peran serta dari berbagai pihak untuk mengurangi kecemasan yang terjadi di masyarakat khususnya di kalangan mahasiswa. Pihak dari pemerintah, institusi pendidikan, keluarga, dan media massa diharapkan dapat meningkatkan upaya nyata dalam menurunkan kecemasan yang terjadi di masyarakat.

\section{Daftar Pustaka}

\section{Saran}

Aulia, D. P. (2018). MEMERANGI BERITA BOHONG DI MEDIA 
JURNAL ILMU KESEHATAN BHAKTI HUSADA:

HEALTH SCIENCES JOURNAL, VOL. 12 No. 01, JUNI 2021

DOI: $10.34305 /$ jikbh.v12i1.274
Ciptaan disebarluaskan di bawah

Lisensi Creative Commons Atribusi-

NonKomersial-BerbagiSerupa 4.0

12(4), 1079-1088.

SOSIAL (Studi Terhadap Gerakan

Masyarakat Anti Fitnah Indonesia)

Skripsi.

https://repository.uinjkt.ac.id/dspac e/bitstream/123456789/41108/1/D

WI PUTRI AULIA-FDK.pdf

Biber, D. D., Melton, B., \& Czech, D. R. (2020). The impact of COVID-19 on college anxiety, optimism, gratitude, and course satisfaction. Journal of American College Health, $\quad 0(0), \quad 1-6$. https://doi.org/10.1080/07448481.2 020.1842424

Cao, Wenjun, Fang, Z., Hou, G., Han, M., Xu, X., Dong, J., \& Zheng, J. (2020). The psychological impact of the COVID-19 epidemic on college students in China, Psychiatry Research. Psychiatry Research, 287. https://doi.org/10.1016/j.psychres.2 020.112934 .

Febriyanti, E. dan, \& Mellu, A. (2020). Tingkat Kecemasan Mahasiswa Keperawatan Dalam Menghadapi Pandemi Covid-19 Di Kota Kupang. NURSING UPDATE: Jurnal Ilmiah Ilmu Keperawatan, 11(3). https://stikes-nhm.ejournal.id/NU/index

Fitria, L., \& Ifdil, I. (2020). Kecemasan remaja pada masa pandemi Covid 19. Jurnal EDUCATIO: Jurnal Pendidikan Indonesia, 6(1), 1. https://doi.org/10.29210/12020259 2

Guslinda, Fridalni, N., \& Minropa, A. (2020). Faktor yang berhubungan dengan tingkat kecemasan lansia pada masa pandemi covid 19. Jurnal Keperawatan Sekolah Tinggi Ilmu Kesehatan Kendal,
Husky, M. M., Kovess-Masfety, V., \& Swendsen, J. D. (2020). Stress and anxiety among university students in France during Covid-19 mandatory confinement. Comprehensive Psychiatry, 102, 152191.

https://doi.org/10.1016/j.comppsyc h.2020.152191

Natalya, W. (2020). Gambaran Tingkat Kecemasan Warga Terdampak Covid 19 Di Kecamatan Comal Kabupaten Pemalang. University Research Colloquium Universitas Aisyiyah Surakarta, 458-463. http://repository.urecol.org/index.p $\mathrm{hp} /$ proceeding/article/view/1230/1 198

Sari, M. K. (2020). Tingkat Stres Mahasiswa S1 Keperawatan Tingkat Satu Dalam Menghadapi Wabah Covid 19 Dan Perkuliahan Daring Di Stikes Karya Husada Kediri. Jurnal Ilmiah Pamenang, 2(1), 31-35.

Satgas Covid-19. (2021). Data Indonesia. covid19.go.id

Vahedian-Azimi A, Moayed M, Rahimi Bashar F, Shojaei S, Ashtari S, \& Pourhoseingholi M. (2020). Comparison of the severity of psychological distress among four groups of an Iranian population regarding COVID-19 pandemic. BMC Psychiatry [revista en Internet] 2020 [acceso 30 de octubre de 2020]; 402(2020): 1-7. BMC Psychiatry, 1-7. https://doi.org/10.1186/s1288802002804-9

Walean, C. J. S., Pali, C., \& Sinolungan, 
J. S. V. (2021). Gambaran Tingkat Kecemasan pada Mahasiswa di Masa Pandemi. Jurnal Biomedik, 13(2),132-143.

https://ejournal.unsrat.ac.id/index.p $\mathrm{hp} / \mathrm{biomedik/article/view/31765/31}$ 240

Wang, C., \& Zhao, H. (2020). The Impact of COVID-19 on Anxiety in Chinese University Students. Frontiers in Psychology, 11(May). https://doi.org/10.3389/fpsyg.2020. 01168

Wang, Y., Di, Y., Ye, J., \& Wei, W. (2021). Study on the public psychological states and its related factors during the outbreak of coronavirus disease 2019 (COVID19) in some regions of China. Psychology, Health and Medicine, 26(1),

13-22. https://doi.org/10.1080/13548506.2 020.1746817

WHO. (2021). Data WHO. covid19, who.int

Zulva, T. N. I. (2020). Covid-19 Dan Kecenderungan Psikosomatis. Journal of Chemical Information and Modeling, 1-4. https://doi.org/10.1017/CBO97811 07415324.004 